\title{
Konsum av risikomatvarer - Beskrivelse av en undersøkelse som skal kartlegge konsum av matvarer med betydning for inntaket av miljøgifter
}

\author{
Helle Margrete Meltzer ${ }^{1}$, Christina Bergsten ${ }^{2}$, Lars Christian Stene ${ }^{1}$, \\ Hein Stigum $^{1}$, Marie Louise Wiborg ${ }^{3}$, Kari Lund-Larsen ${ }^{3}$ og Jan Alexander ${ }^{1}$ \\ ${ }^{\text {I}}$ Statens institutt for folkehelse, Oslo \\ ${ }^{2}$ Institutt for ernceringsforskning, Universitetet i Oslo \\ ${ }^{3}$ Statens nceringsmiddeltilsyn, Oslo
}

Korrespondanse: Helle Margrete Meltzer, Avdeling for miljømedisin, Folkehelsa, Postboks 4404 Torshov, 0403 Oslo Telefon: 22042337 telefax: 22042243 e-post: helle.margrete.meltzer@folkehelsa.no

\begin{abstract}
SAMMENDRAG
I perioden 1999-2001 vil det bli gjennomført tre kostholdsundersøkelser som til sammen skal kartlegge konsum av matvarer med betydning for inntaket av miljøgifter i Norge, fortrinnsvis kadmium, kvikksølv, PCB og dioksiner. Disse giftene finnes hovedsakelig i krabbe, flatfisk, skjell, gjedde og abbor, lever eller nyre fra vilt og viltvoksende sopp. Fordi gjennomsnittskonsumet er lavt, spørres det ikke spesifikt om disse matvarene i landsdekkende kostholdsundersøkelser som 'Norkost'. Hensikten med studien er å kunne gi en bedre beskrivelse av eksponeringsfordelingen i befolkningen med tanke på miljøgifter. Fordelingen er antakelig skjev, dvs. et stort antall personer ventes å ha et lavt inntak og noen få personer ventes å ha et relativt høyt inntak av de undersøkte stoffene. Eventuelle ukjente risikogrupper vil kunne avdekkes, og det er av stor interesse å undersøke hvor stor eksponeringen i de utsatte gruppene er.

Del A av undersøkelsen er landsdekkende og omfatter en postal frekvensundersøkelse til 10000 tilfeldig valgte personer mellom 18 og 79 år. Del B omfatter en postal frekvensundersøkelse til 6000 tilfeldig valgte personer i seks kommuner, der tre er kystkommuner og tre er innlandskommuner. Kommunene blir valgt ut fra kjennskap til god tilgang på de aktuelle matvarene. Vi antar at der tilgangen på matvarene er god, er konsumet høyere. Del C av undersøkelsen vil omfatte høykonsumenter av aktuelle matvarer, valgt fra del B av undersøkelsen. Dette vil være en dybdestudie der analyser av miljøgifter i blod, hår og urin også skal inngå.

Undersøkelsen er den første i sitt slag her til lands og vi kjenner ikke til at tilsvarende studier er gjort i andre land. Hensikten med artikkelen er å gi en beskrivelse av undersøkelsen i en tidlig fase av gjennomføringen.
\end{abstract}

\section{Meltzer HM, Bergsten C, Stene LC, Stigum H, Wiborg ML, Lund-Larsen K, Alexander J. Consumption of contaminated foods - Description of a dietary survey focusing on foods containing environmental contaminants. Nor J Epidemiol 2000; 10 (1): 51-56.}

\section{ENGLISH SUMMARY}

In 1999-2001 three dietary surveys will be conducted, focusing on the consumption patterns of foods which may contain environmental contaminants, primarily cadmium, mercury, polyclorinated biphenyls (PCBs) and dioxins. These contaminants are mainly found in crab, flatfishes, crustaceans, perch and pike, liver and kidney from game, and wild mushrooms. Because the average consumption in the population is low, these food items are not specifically asked about in national dietary surveys. The aim of the study is to give a better description of the exposure distribution of environmental contaminants in the population. The distribution is probably skewed, i.e. a large percentage is expected to have a low intake while a small percentage is expected to have a relatively high intake of the various contaminants. Unknown risk groups may be unravelled, and a quantification of their intake will be possible.

Part A of the survey encompasses a nation-wide postal qualitative food frequency questionnaire to ten thousand randomly chosen persons between 18 and 79 years of age. Part B encompasses a postal quantitative food frequency questionnaire to six thousand randomly chosen persons from three coastal and three inland municipalities. The municipalities will be chosen on the basis that the supply of fish and game is ample. We assume that given high access to these foods, consumption will be above average. Part $\mathrm{C}$ of the survey encompasses high consumers of the foods in question, selected from part B of the survey. This will be an in-depth study where analyses of environmental contaminants in blood, urine and hair are included.

This survey is the first of its kind in Norway. As far as we know, no similar studies have been conducted elsewhere. The purpose of the article is to describe the survey in an early phase of its conduction. 


\section{INNLEDNING}

Miljøgifter er stoffer som selv i små konsentrasjoner kan gi skadeeffekter på naturmiljøet ved at de er giftige og kan oppkonsentreres til skadelige konsentrasjoner i næringskjeden og/eller ha særlig lav nedbrytbarhet (1). Mat og drikke er vår kilde til næringsstoffer, men kan også bidra til økt eksponering for en rekke miljøgifter, bl.a. kadmium, kvikksølv, polyklorerte bifenyler (PCB) og dioksiner (1). Miljøgifter karakteriseres særlig ved at utskillingsgraden fra kroppen er lav, slik at selv lav eksponering, men over mange år, kan føre til helseskader (2). Et eksempel er kadmium, som akkumuleres i nyrene og på sikt kan føre til nyreskader. På 1990-tallet er denne akkumuleringen blitt knyttet til bl.a. økt risiko for osteoporose (3). Kosten er den viktigste kilden til kadmium dersom man er ikke-røyker og ikke er yrkeseksponert.

Både nasjonalt og internasjonalt (Den Europeiske Union EU, Verdens Helseorganisasjon WHO) arbeides det med risikovurderinger i forhold til eksponering og helseeffekter av miljøgifter.

I Norge har punktutslipp av miljøgifter fra fabrikkanlegg fått en del oppmerksomhet. I de tilfellene dette har medført økt nivå av giftene i lokale matvarer, har det vært gjennomført flere undersøkelser av utsatte grupper. Johansen et al. (4) fant bl.a. at inntaket av dioksiner lå over det tolerable ukentlige inntaksnivået hos høykonsumenter av fisk og krabbe fra Frierfjorden i Telemark.

En rekke nyere studier antyder at den skadelige effekten av flere miljøgifter kan oppstå ved lavere eksponeringsnivåer enn tidligere antatt. Et eksempel er den påviste sammenhengen mellom et moderat inntak av kadmium og øket risiko for nyreskader. Funnene, som bl.a. kommer fra Belgia (5), har bidratt til at man i EU nå diskuterer å senke verdien for tolerabelt ukentlig inntak (PTWI) av kadmium. Selv inntaksnivåer langt under PTWI kan settes i sammenheng med biokjemiske endringer i kroppen, bl.a. vist $i$ en norsk studie, der kvikksølvinntaket var positivt korrelert med endringer i blodets LDL-konsentrasjon (6).

Kostholdets betydning for eksponeringen i befolkningen kan bare vurderes når man har konsumdata, både $\mathrm{i}$ gjennomsnittsbefolkningen og hos høykonsumenter. Statens næringsmiddeltilsyn (SNT) og Statens institutt for folkehelse (Folkehelsa) har derfor startet en undersøkelse som skal framskaffe representative data for konsum av matvarer som kan ha høyt innhold av helseskadelige stoffer, dvs. ulike sorter fisk, vilt, innmat av fisk og vilt, skalldyr, sopp og hvetekli.

\section{Problemstillinger}

Studien skal danne utgangspunkt for overvåking av befolkningen mht. konsum og helseeffekter av risikomatvarer. Studien skal gi en beskrivelse av eksponeringsfordelingen i befolkningen med tanke på miljøgifter. Eventuelle ukjente risikogrupper vil kunne avdekkes, og eksponeringen i de utsatte gruppene estimeres.
Følgende spørsmål ønskes besvart:

- Hvor ofte spises risikomatvarer i befolkningen generelt, i utvalgte områder og hos individene med høyest konsum?

- Vil konsumet hos individer med høy eksponering reflekteres i høyere konsentrasjoner av stoffene $\mathrm{i}$ blod, urin eller hår?

- Kan eksponeringen hos høykonsumenter føre til overskridelse av tolerabelt inntak og eventuelt utgjøre en helserisiko?

\section{Risikomatvarer}

Begrepet risikomatvare defineres i denne undersøkelsen som en matvare som kan inneholde høy konsentrasjon av en nærmere bestemt miljøgift. Hvilke matvarer som kommer inn under definisjonen er avhengig av hvilket stoff som undersøkes, lokale forurensningsforhold og hvilke matvarer som kan være kilder for stoffet.

Undersøkelser av forurensede fjordområder viser at fisk, fiskelever og skalldyr, spesielt krabber, kan inneholde til dels store mengder miljøgifter $(7,8)$. Det er i mange tilfeller gitt råd om å begrense konsumet av sjømat fra disse områdene, men det finnes lite kunnskap om hvor mye fisk og skalldyr folk i kystområdene faktisk spiser. Dette gjelder også for en del andre matvarer som kan inneholde miljøgifter eller andre fremmedstoffer, f.eks. ferskvannsfisk, innmat av vilt og sopp. Disse risikomatvarene betyr lite for inntaket av næringsstoffer i gjennomsnittsbefolkningen fordi de vanligvis spises i små mengder. Det blir derfor ikke lagt spesiell vekt på å skaffe konsumdata for disse matvarene i vanlige kostholdsundersøkelser. Landsdekkende kostholdsundersøkelser som Norkost vil ikke fange opp grupper som spiser mye av denne type risikomatvarer, ganske enkelt fordi det ikke spørres spesifikt om de matvarene som kan inneholde høye konsentrasjoner av miljøgifter i disse undersøkelsene.

Matvarene i tabell 1 er sentrale i undersøkelsen fordi de kan inneholde til dels store mengder miljøgifter.

Flere av matvarene i tabell 1 er med i 'Norkost', men som del av samlespørsmål. For eksempel inngår reinsdyr i et samlespørsmål med elg og hjort under spørsmålet 'Stek', og flyndre og kveite inngår i et felles spørsmål med steinbit og uer. Også krabbe og reker inngår i samme spørsmål i 'Norkost'. Fordi krabbe og reker akkumulerer til dels forskjellige miljøgifter, må konsumet av de to matvarene registreres hver for seg, hvis dataene skal brukes til å estimere inntaket av ulike miljøgifter.

\section{Miljogifter som er med i undersokelsen}

Undersøkelsen er i første omgang begrenset til å omfatte miljøgiftene kvikksølv, kadmium, PCB og dioksiner, men vil senere også kunne inkludere bl.a. arsen og radionuklider. Kvikksølv, kadmium, PCB og dioksiner 
Tabell 1. Matvarer som kan inneholde til dels store mengder miljøgifter.

\begin{tabular}{ll}
\hline Matvare & Begrunnelse \\
\hline Krabbe & Akkumulerer miljøgifter, spesielt kadmium, dioksiner og PCB \\
Flyndre o.l. & $\begin{array}{c}\text { Lever på bunnen, er stasjonær, er med i andre overvåkingsprogrammer, } \\
\text { akkumulerer arsen, PCB og dioksiner }\end{array}$ \\
Lever av fisk & Akkumulerer miljøgifter som dioksiner og PCB \\
Reker & Akkumulerer miljøgifter i hodet. Arsen i hele reken. \\
Skjell (blåskjell, o-skjell o.l.) & Akkumulerer PAH og tungmetaller \\
Kveite (hellefisk) eller tunfisk & Blir store og gamle, akkumulerer kvikksølv \\
Gjedde/abbor & Rovfisker, akkumulerer kvikksølv \\
Reinsdyr & Akkumulerer radionuklider \\
Lever eller nyre fra vilt & Akkumulerer flere miljøgifter, spesielt kadmium \\
Sopp (viltvoksende) & Akkumulerer radionuklider \\
Hvete- og havrekli, evt. sammalt mel & Konsentrasjonen av kadmium kan være høy i den ytre delen (skallet) av kornet \\
\hline
\end{tabular}

utgjør fire av de ni stoffgruppene SFT plasserer i Gruppe 1, dvs. 'Stoffer som representerer et betydelig miljøproblem i Norge' (1). De har til felles at mat og drikke er den viktigste eksponeringsveien fordi de oppkonsentreres i næringskjeden og har lang biologisk halveringstid. Vi har relativt gode nasjonale data for nivåene av kvikksølv, kadmium, PCB og dioksiner som kan forekomme i risikomatvarene i denne undersøkelsen. Ved å kombinere disse analysedataene med konsumdata for relevante matvarer, kan simuleringsmetoder brukes til å estimere en eksponeringsfordeling for befolkningen.

\section{UTVALG, METODE OG DESIGN}

Undersøkelsen skal gjennomføres i tre til dels uavhengige spørreundersøkelser på tre ulike nivåer:

\section{Nivå A. Landsdekkende tverrsnittundersøkelse}

Postal frekvensundersøkelse om konsum (uten mengder) av utvalgte risikomatvarer ble sendt til et representativt utvalg av befolkningen. Vi har antatt at enkelte av de aktuelle matvarene, for eksempel gjedde, spises av ca. $1 \%$ (variasjon $0-2 \%$ ) av den generelle befolkningen i Norge. For å få et rimelig presist estimat på landsbasis har vi beregnet at vi bør ha svar fra 6-7000 personer. Ut fra en antatt svarprosent på 60-70 ble et tilfeldig utvalg på 10000 personer mellom 18 og 79 år trukket fra Folkeregisteret, og fikk tilsendt et tosiders spørreskjema (se vedlegg 1).

Undersøkelsen er anonym, men vi har informasjon om kjønn, alder og postnummer på hele utvalget. Representativiteten til gruppen som svarer vil derfor kunne sammenliknes mht. kjønn, alder og postnummer både mot hele utvalget og mot sammensetningen av hele befolkningen ved hjelp av data fra Statistisk sentralbyrå.

Den postale delen av denne undersøkelsen ble gjennomført primo november (første utsending) og ultimo november (purrebrev) 1999, og pr. 31.12.1999 var svarprosenten ca. 60. Det optisk lesbare skjemaet (Vedlegg 1) ble scannet i februar 2000 og dataene vil bli bearbeidet i løpet av våren 2000 .

\section{Nivå B: Regional tverrsnittsundersøkelse}

Postal kvantitativ frekvensundersøkelse i tre kyst- og tre innlandsområder hvor konsumet av minst to risikomatvarer antas å være høyt. Spørreskjemaet vil omfatte de samme matvarene som i nivå $\mathrm{A}$, men vil bli mer detaljert, både med hensyn til frekvenser og antall matvarer. Siden vi forventer at en relativt lav andel av befolkningen spiser en eller flere av de aktuelle matvarene, kan vi ikke forvente at del A vil gi oss tilstrekkelig presise estimater til å definere kommuner med høyt konsum. Utvalg av områdene med høyt konsum vil derfor bli gjort ved hjelp av forskjellige offentlige statistikker (for eksempel jaktstatistikk), kontakt med viltnemnder, blåskjellinformasjonen, leveringssteder for skjellfangst, kommunale næringsmiddeltilsyn med mer. I områdene som velges skal innbyggerne ikke tidligere ha fått råd om å redusere inntaket av de aktuelle matvarene. Til sammen ca. 3000 tilfeldig valgte individer $\mathrm{i}$ innland og ca. 3000 tilfeldig valgte i kystområdene vil bli spurt om å delta $\mathrm{i}$ nivå $\mathrm{B}$. Vi har foreløpig ikke tatt stilling til om barn og ungdom skal inngå i denne delen av undersøkelsen.

\section{Nivå C: Lokal dybdeundersøkelse}

Dybdeundersøkelse hos 'indikator-familier' (familier med spesielt høyt konsum av aktuelle matvarer). Disse familiene velges ut fra respondentene i B. Deltakerne vil bli bedt om å delta i en kostholdsregistrering (hele kosten) samt avgi blod-, hår- og urinprøver. Detaljer omkring kostholdsregistreringen er ennå ikke avklart. I første omgang planlegges det å analysere for konsentrasjonen av miljøgiftene kadmium, kvikksølv, PCB og dioksin. Innholdet av de samme stoffene skal også analyseres i en matkurv som settes sammen på grunn- 
lag av gjennomsnittlig og høyt inntak av matvarene i indikator-familiene. En gruppe lav- eller normalkonsumenter fra de samme kommunene velges ut som kontroller. Antall familier som skal delta på nivå $\mathrm{C}$ bestemmes ut fra resultatene av B. Del C skal gjennomføres i 2001.

\section{Gjennomforing}

Folkehelsa har hovedansvar for utsending og innsamling av spørreskjemaene, optisk lesing, etablering av rådatafiler og statistiske analyser av materialet. Konsesjon fra datatilsynet blir søkt for hvert av de tre nivåene. Etisk komité får separat søknad for hver av de tre undersøkelsene. Gjennomføringsperioden for undersøkelsen er 1999-2001.

\section{Validering av metodene}

Resultatene kan i prinsippet valideres på to forskjellige måter: enten ved å sammenlikne resultatene med svar fra andre kostholdsundersøkelser, eller ved å sammenlikne med biologiske målinger, dvs. biomarkører for inntak i blod, urin eller hår. Kvikksølvmengden i hår og blod reflekterer for eksempel godt kostinntaket av metylkvikksølv, mens kadmiumkonsentrasjonen i urin reflekterer kadmiuminntaket over tid. Ved å inkludere en del spørsmål om vanlige matvarer (torsk, sei osv.) i den landsdekkende undersøkelsen, vil konsumfrekvensen i undersøkelsen kunne sammenliknes med tilsvarende informasjon fra andre undersøkelser. Vi anser dette som adekvat validering i forhold til problemstillingene våre i del $\mathrm{A}$.

Undersøkelsene på nivå $\mathrm{B}$ og $\mathrm{C}$ er ikke planlagt $\mathrm{i}$ detalj enda, men vi antar at blod,- hår- og urinanalysene som samles i dybdeundersøkelsen vil kunne brukes til å validere begge disse nivåene.

\section{ANDRE STUDIER}

Så vidt vi vet er tilsvarende studier, med hovedvekt på konsum av flere risikomatvarer $\mathrm{i}$ et representativt utvalg av befolkningen, ikke gjennomført i noe land. Konsum av enkeltmatvarer, for eksempel krabbe, er blitt fanget opp dersom de inngår i nasjonale kostholdsundersøkelser, men et så bredt spekter av risikomatvarer i en befolkning er ikke undersøkt.

I Sverige er det gjennomført flere store undersøkelser med hovedfokus på fiskere og deres eksponering for marine miljøgifter, bl.a. dioksin (9), PCB (10) og kvikksølv $(11,12)$. De samme yrkesgruppene ble studert $\mathrm{i}$ forhold til risiko for kreft og hjerte- og karsykdommer (13). Fiskerne hadde høyere blodkonsentrasjoner enn kontrollgruppene av alle stoffene som ble undersøkt, og det ble funnet en øket risiko for mage- og hudkreft blant høykonsumenter av fet fisk. Den samme gruppen hadde tendens til redusert risiko for hjerte-og-kar-sykdommer. Det er viktig å merke seg at på grunn av den lave utskiftingsgraden av vannmassene i Østersjøen, har fisken derfra, spesielt fete fiskeslag, betydelig høyere konsentrasjoner av miljøgifter enn fisk fra for eksempel norske-kysten.

På Færøyene spises det tradisjonelt mye grindhval og andre sjøpattedyr høyt oppe i næringskjeden. Omfattende undersøkelser har vist at blodnivåene av kvikksølv, selen, arsen og PCB er relatert til inntaket av sjømat (14). Nylig publiserte resultater fra en studie på færøyske barn viste at biomarkører for eksponering av metylkvikksølv, bl.a. i navlestrengsblod, kunne settes i sammenheng med tegn på nevrotoksiske skader i 7-års-alderen (15). Inuit-kvinner i Canada, en annen gruppe med tradisjonelt høy inntak av marine dyr, hadde 2 til 10 ganger høyere konsentrasjoner av PCB i morsmelken enn kvinner fra Quebec-området $(16,17)$. Den helsemessige vurderingen av dette inntaket, som ligger godt over aksepterte grenseverdier, er ennå ikke publisert (18).

Det finnes også en rekke andre undersøkelser av fraksjoner av befolkninger med høy eksponering for miljøgifter, bl.a. fra Japan, Taiwan og USA. I nordisk sammenheng er en finsk studie av høykonsumenter av innlandsfisk en av de mest interessante (19). Høykonsumenter av mager ferskvannsfisk hadde betydelig høyere konsentrasjoner av kvikksølv i hår, blod og urin enn lavkonsumenter. Menn i den høyeste tertilen av fordelingen av kvikksølvkonsentrasjoner i hår hadde en dobling av risiko for å få akutt hjerteinfarkt og 2,9 ganger øket risiko for kardiovaskulær død i forhold til menn i den laveste tertilen. Forfatterne foreslår at kvikksølv-effekten først og fremst skyldes øket lipid-peroksidasjon. Både i Sverige og Norge advares gravide kvinner mot å spise innlandsfisk for å unngå de nevrotoksiske skadene kvikksølv kan ha på fosteret.

Resultatene fra vår undersøkelse vil gi et svært godt utgangspunkt for å vurdere hvor utsatt hele eller deler av den norske befolkningen er for de miljøgiftene vi skal undersøke. De vil kunne danne utgangspunkt for fremtidige studier av sammenhengen mellom miljøgifter og helse. Næringsmiddelmyndighetene vil bruke resultatene til å vurdere om spesifikke tiltak må iverksettes for å redusere risiko for helseskader blant utsatte befolkningsgrupper. Større kunnskap om inntaket av risikomatvarer vil gjøre det lettere å gi riktig og avbalansert informasjon om risikoen forbundet med miljøgifter i mat. Med større kunnskap og viten om konsumet av risikomatvarer vil noen av usikkerhetene ved dagens risikovurderinger for inntak av miljøgifter bli mindre. 


\section{REFERANSER}

1. Miljøgifter i Norge. SFT Rapport nr. 93:22, 1993.

2. Järup L, Berglund M, Elinder CG, Nordberg G, Vahter M. Health effects of cadmium exposure - a review of the literature and a risk estimate. Scand J Work Environ Health 1998; 24 (suppl): 1-52.

3. Järup L, Alfven T, Persson B, Toss G, Elinder CG. Cadmium may be a risk factor in osteoporosis. Occup Environ Med 1998; 55: 435-9.

4. Johansen HR, Alexander J, Rossland OJ, Planting S, Løvik M, Gaarder PI, Gdynia W, Bjerve KS, Becher G. PCDDs, PCDFs, and PCBs in human blood in relation to consumption of crabs from a contaminated fjord area in Norway. Environ Health Perspect 1996; 104: 756-64.

5. Buchet JP, Lauwerys R, Roels H, Bernard A, Bruaux P, Claeys F, et al. Renal effects of cadmium body burden of the general population. Lancet 1990; 336: 699-702.

6. Meltzer HM, Mundal HH, Alexander J, Bibow K, Ydersbond T. Does dietary arsenic and mercury affect cutaneous bleeding time and blood lipids in humans? Biol Trace Elem Res 1994; 46: 135-53.

7. Fremmedstoffer og smittestoffer - holder maten mål? SNT, 1995.

8. Berg V, Eriksen G, Iversen PE. Forslag til strategi for kartlegging av miljøgifter i marine organismer i norske havner og fjorder. SNT-rapport 10. Statens næringsmiddeltilsyn, 1997.

9. Svensson B-G, Nilsson A, Hansson M, Rappe C, Åkesson B, Skerfving S. Exposure to dioxins and dibenzofurans through the consumption of fish. $N$ Engl J Med 1991; 324: 8-12.

10. Asplund L, Svensson BG, Nilsson A, Eriksson U, Jansson B, Jensen S, Wideqvist U, Skerfving S. Polychlorinated biphenyls, 1,1,1-trichloro-2,2-bis(p-chlorophenyl)ethane (p,p'-DDT) and 1,1-dichloro-2,2-bis(pchlorophenyl)-ethylene (p,p'-DDE) in human plasma related to fish consumption. Arch Environ Health 1994; 49: 477-86.

11. Svensson BG, Schutz A, Nilsson A, Åkesson I, Åkesson B, Skerfving S. Fish as a source of exposure to mercury and selenium. Sci Total Environ 1992; 126: 61-74.

12. Svensson BG, Nilsson A, Jonsson E, Schutz A, Åkesson B, Hagmar L. Fish consumption and exposure to persistent organochlorine compounds, mercury, selenium and methylamines among Swedish fishermen. Scand J Work Environ Health 1995; 21: 96-105.

13. Svensson BG, Mikoczy Z, Stromberg U, Hagmar L. Mortality and cancer incidence among Swedish fishermen with a high dietary intake of persistent organochlorine compounds. Scand J Work Environ Health 1995; 21: 106-15.

14. Grandjean P, Weihe P, Needham LL, Burse VW, Patterson DG Jr, Sampson EJ, Jorgensen PJ, Vahter M. Relation of a seafood diet to mercury, selenium, arsenic, and polychlorinated biphenyl and other organochlorine concentrations in human milk. Environ Res 1995; 71: 29-38.

15. Grandjean P, Budtz-Jorgensen E, White RF, Jorgensen PJ, Weihe P, Debes F, Keiding N. Methylmercury exposure biomarkers as indicators of neurotoxicity in children aged 7 years. Am J Epidemiol 1999; 150: 301-5.

16. Dewailly E, Ayotte P, Bruneau S, Laliberte C, Muir DC, Norstrom RJ. Inuit exposure to organochlorines through the aquatic food chain in arctic Quebec. Environ Health Perspect 1993; 101: 618-20.

17. Ryan JJ, Dewailly E, Gilman A, Laliberte C, Ayotte P, Rodrigue J. Dioxin-like compounds in fishing people from the Lower North Shore of the St. Lawrence River, Quebec, Canada. Arch Environ Health 1997; 52: 30916.

18. Van Oostdam J, Gilman A, Dewailly E, Usher P, Wheatley B, Kuhnlein H, et al. Human health implications of environmental contaminants in Arctic Canada: a review. Sci Total Environ 1999; 230: 1-82.

19. Salonen JT, Seppanen K, Nyyssonen K, Korpela H, Kauhanen J, Kantola M, et al. Intake of mercury from fish, lipid peroxidation, and the risk of myocardial infarction and coronary, cardiovascular, and any death in eastern Finnish men. Circulation 1995; 91: 645-55. 
Vedlegg 1. Spørreskjema for den landsdekkende tverrsnittsundersøkelsen om konsum av risikomatvarer.

ข้

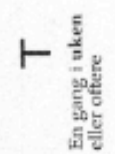

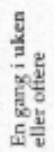

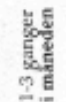<smiles>[C]1[C]=C1</smiles>

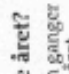

券
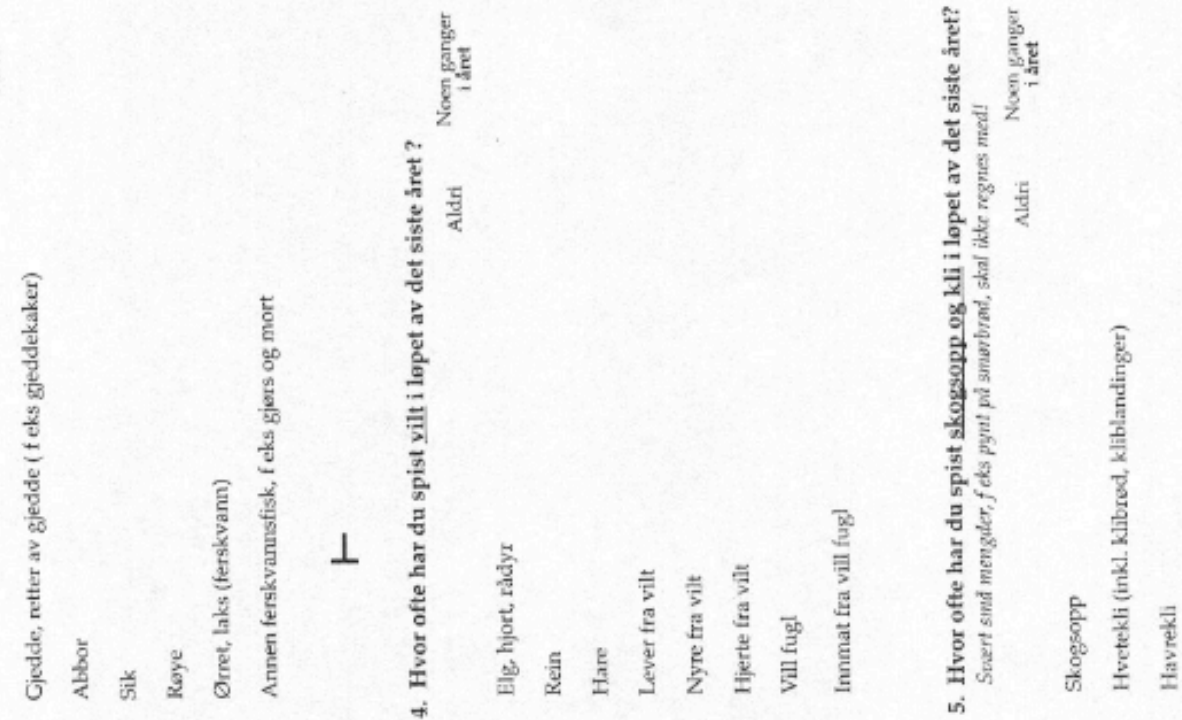

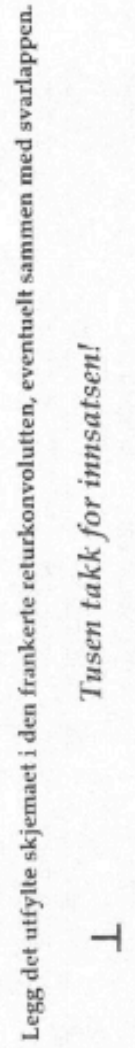

营灵

.

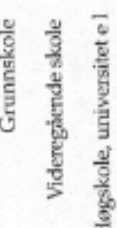<smiles>[C]1CCCC1</smiles>

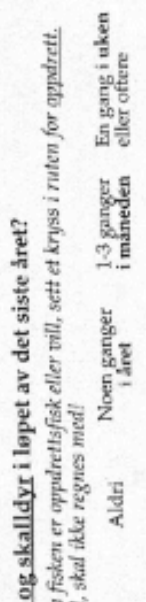

कี

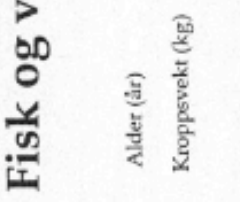

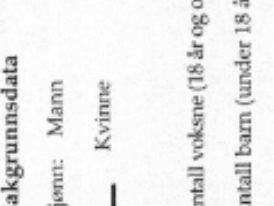
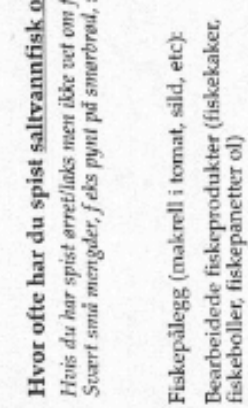

$\mathrm{T}$

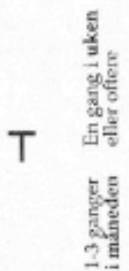

(2)

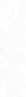

